\title{
TRAVIS DURDEN, MYTHS AND IDOLS. GWIEZDNE WOJNY W ARTYSTYCZNYM ENTOURAGE'U
}

Katarzyna BALBUZA

\section{ABSTRACT}

\section{TRAVIS DURDEN, MYTHS AND IDOLS. STAR WARS IN THE ARTISTIC ENCOURAGE}

The project Myths and Idols, by the French photographer Travis Durden, came into being in 2015 by means of digital technology. The artist processed photos of nine selected modern sculptures, mostly related to ancient matters, in order to provide them with the attributes or heads belonging to the heroes of the famous Star Wars saga. The sculptures chosen by Durden for his project had been created by European artists (French sculptors and one Italian master) and they are exclusively of an early modern provenance (arising from the Renaissance, Classicism, and Neoclassicism). Not a single work of ancient art is included. However, the classical (ancient) art itself became an object of the Parisian sculptor's interest in terms of taking early modern art into account as the artists of the latter patterned themselves on ancient samples and picked up ancient subject matters. Likewise, Star Wars in turn constitutes a product of the American pop-culture frequently referring to motifs which had originated in ancient culture. The article discusses all nine photo collages and the whole project is being interpreted. Myths and Idols offers an example of the double reception of ancient culture - the early modern and contemporary ones.

\section{KEYWORDS:}


Gwiezdne wojny (ang. Star Wars), saga w reżyserii George’a Lucasa, to już nie tylko światowy przebój współczesnej kinematografii - to rozbudowane uniwersum różnego rodzaju produkcji medialnych ${ }^{1}$, fenomen socjologiczny i kulturowy mający niewiarygodną siłę oddziaływania w wielu dziedzinach kultury popularnej i sztuki ${ }^{2}$. Fascynuje i inspiruje wielu obserwatorów i uczestników kultury popularnej i sztuki współczesnej. Jednym z nich jest nieznany z nazwiska fotograf z Paryża, tworzący pod pseudonimem Travis Durden (ur. 1975) ${ }^{3}$. Na swojej stronie internetowej informuje, że posługiwanie się pseudonimem ma na celu wyeksponowanie sztuki, nie jej autora ${ }^{4}$. To oryginalne podejście prezentuje twórca, który ma w swoim dorobku kilka projektów fotograficznych. Wszystkie zostały wystawione w Galerie Sakura ${ }^{5}$, niektóre z nich doczekały się ekspozycji także w innych galeriach lub miejscach publicznych w Europie i Stanach Zjednoczonych. Można się też z nimi zapoznać online, na stronie internetowej Travisa Durdena ${ }^{6}$ lub na jego portalach społecznościowych Facebook i Instagram ${ }^{7}$, gdzie informuje o swoich projektach i wystawach oraz zamieszcza linki do artykułów prasowych na temat swojej sztuki.

Przedmiotem niniejszych rozważań jest pierwszy projekt Durdena pt. Myths and Idols / Birth of a New Myth (2015), który wyrósł z zainteresowań oscylujących, najogólniej rzecz ujmując, wokół kultury popularnej, sztuki, historii, religii i mitologii. W facebookowym opisie działalności Durdena idea, która mu przyświeca w procesie twórczym, została wyłożona w następujących słowach:

Por. np. cykl Star Wars Art Series nowojorskiego wydawnictwa Abrams Books: Star Wars Art: Visions, New York 2010; Star Wars Art: Comics, New York 2011; Star Wars Art: Illustration, New York 2012; Star Wars Art: Concept, New York 2013; Star Wars Art: Posters, New York 2014; The Art of Star Wars: The Force Awakens, New York 2015.

$\mathrm{Na}$ temat fenomenu Gwiezdnych wojen i ich oddziaływania na szeroko rozumianą kulturę napisano już bardzo wiele. Zob. np. Finding the Force of the Star Wars Franchise. Fans, Merchandise, \& Critics, ed. by M.W. Kapell, J.S. Lawrence, New York 2006; Culture, Identities and Technology in the Star Wars Films: Essays on the Two Trilogies, ed. by C. Silvio, T.M. Vinci, Jefferson 2007.

Pseudonim artysty powstał z kompilacji ról filmowych dwóch aktorów amerykańskich. Z jednej strony, nawiązuje do roli Roberta de Niro (Travis Bickle) w filmie Taxi Driver (1976) w reżyserii Martina Scorsese, z drugiej, do roli Tylera Durdena, którą odgrywał Brad Pitt w filmie Fight Club (1999). Zob. S. Dunne, French Artist Manipulates Statues to Create Star Wars Photos, „Hartford Courant” [online], 30 grudnia 2015 [dostęp: 18 marca 2017]. Dostępny w World Wide Web: http://www.courant.com/entertainment/museums-galleries/hc-ebk-gallery-star-wars-0103-20151230-story.html.

Travis Durden: „Travis Durden is a pseudonim, as the Parisian artist behind the project would prefer his art be the center of attention, not himself". Zob. online: http://www.travisdurden.com/index.php/biographie [dostęp: 18 marca 2017].

Galerie Sakura mieści się w Paryżu (Rue du Bourg Tibourg 21, 75004 Paris) i specjalizuje w wystawianiu i sprzedaży współczesnych prac fotograficznych. Strona internetowa galerii: https://www.galerie-sakura.com.

http://www.travisdurden.com/index.php/biographie.

https://www.facebook.com/travisdurden; https://www.instagram.com/travis_durden_art. 
Fascinated by the construction of myths \& idols, he interrogates how we, as humans, determine what will be raised to popular culture or elevated to divine cult, and how history has influenced us in making the choice ${ }^{8}$.

W szczególności zainteresował artystę proces i mechanizm tworzenia mitów ${ }^{9}$, dokonywania wyborów co do zjawisk, które zasługują z jakichś względów na to, aby je traktować jako nadzwyczajne i godne kultu. W procesie tym znacząca rola przypada historii. Na swojej stronie facebookowej artysta podaje, że przyświecał mu zamysł skonfrontowania i połączenia ze sobą produktów współczesnej kultury popularnej z nowożytnymi wyobrażeniami klasycznych tematów ${ }^{10}$. Realizując go, miał nadzieję uzyskać odpowiedź na pytanie o mechanizm konstruowania mitów oraz podobieństwa semantyczne między obiektami kultu w różnych okresach historycznych. Projekt ten miał być zapowiedzią kolejnych, w których zamierzał rozważać podobne kwestie ${ }^{11}$. Analizując rzeźbiarskie zabytki sztuki europejskiej, doszedł do wniosku, że sposoby konstrukcji mitów przez antyczne i współczesne społeczeństwa są niemal identyczne. W wywiadzie udzielonym drogą e-mailową amerykańskiej gazecie „Hartford Courant” stwierdził:

At any time, people have always needed to believe in idols to give a moral sense to their lives. Idols and myths are there to instill in us principles of right or wrong... ${ }^{12}$.

Zainspirowany kolekcją rzeźb w paryskim Luwrze (Musée du Louvre) Durden wybrał kilka arcydzieł sztuki europejskiej, sfotografował je, a następnie poddał procesowi obróbki komputerowej, cyfrowo dodając im atrybuty wybranych przez

http://www.travisdurden.com/index.php/biographie [dostęp: 18 marca 2017].

Na temat znaczenia mitu w odniesieniu do Gwiezdnych wojen zob. np. A. Gordon, Star Wars: A Myth for Our Time, Literature, „Film Quarterly” 1978, 6.4, s. 314-326; M. Henderson, Star Wars: The Magic Myth, New York 1997; J.S. Lawrence, Joseph Campbell, George Lucas and the Monomyth [w:] M.W. Kapell, J.S. Lawrence, dz. cyt., s. 21-34; S.P. McVeight, The Galactic Way of Warfare [w:] tamże, s. 35-58; M.J. Kinnucan, Pedagogy of (the) Force: The Myth of Redemptive Violence [w: ] tamże, s. 59-74; Myth, Media and Culture in Star Wars: An Anthology, ed. by D. Brode, L. Deyneka, Lanham-Toronto-Plymouth 2012; J.C. McDowell, „Unlearn what you have learned” (yoda): the Critical Study of the Myth of Star Wars [w: Understanding Religion and Popular Culture. Theories, Themes, Products and Practices, ed. by T.R. Clark, D.W. Clanton, Jr., New York 2012, s. 104-117. Zob. też G. Lucas, Of Myth and Men: A Conversation between Bill Moyers and George Lucas on the Meaning of the Force and the True Theology of Star Wars, „Time” 153.16[online], 18 kwietnia 1999, s. 91-94 [dostęp: 11 sierpnia 2017]. Dostępny w World Wide Web: http://content.time.com/time/magazine/article/0,9171,23298,00.html.

$10 \mathrm{https}: / /$ www.facebook.com/pg/travisdurden/about/?ref=page_internal [dostęp: 11 sierpnia 2017]: „This series is the first of a new process in which he questions the similarities between objects of cult from different periods in time by confronting them head on. The idea of mixing contemporary culture with Renaissance depictions of classical subjects...”.

11 https://www.facebook.com/pg/travisdurden/about/?ref=page_internal [dostęp: 11 sierpnia 2017].

12 „Hartford Courant” [online], 30 grudnia 2015 [dostęp: 18 marca 2017]. Dostępny w World Wide Web: http://www.courant.com/entertainment/museums-galleries/hc-ebk-gallery-star-wars-0103-20151230-story.html. 
siebie bohaterów sagi Gwiezdne wojny. W wyniku tej modyfikacji powstały fotokolaże wyobrażające „rzeźby”, które Durden wystawia w galeriach sztuki i innych miejscach publicznych. Na pytanie o to, czym się kierował w wyborze bohaterów dla swoich nowych „rzeźb”, jeśli chodzi o tak oryginalne zestawienie - postacie z legend antycznych versus bohaterowie Gwiezdnych wojen - odpowiedział, że zamierzał ukazać kontrast dobra i zła wyrażający się w ludzkiej naturze:

Much like the figures from ancient legends, the characters in 'Star Wars' have a dimension of heroes and villains, and crystallize what is best and worst in human nature. In that sense, they perfectly fit together ${ }^{13}$.

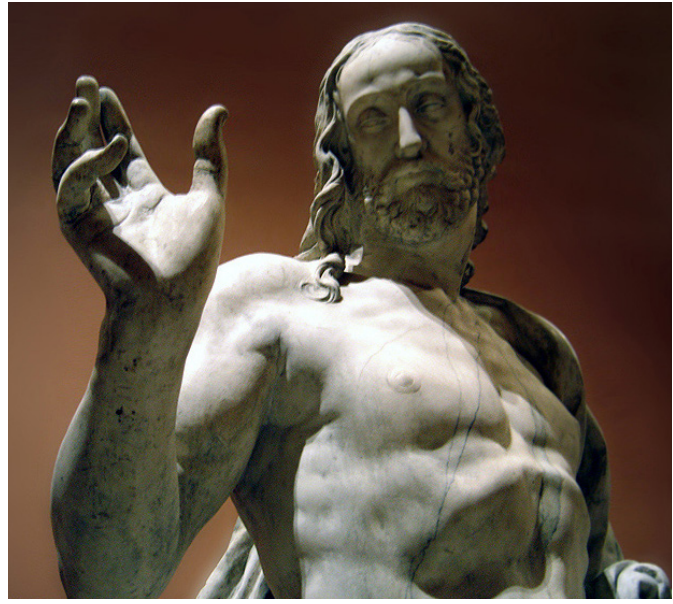

Ryc. 1a. Germain Pilon (ok. 1537-1590), fragment grupy rzeźbiarskiej pt. La Résurrection (ok. 1572). Marmur. Musée du Louvre. Fot. R.A. Frantz (c) Wikimedia Commons, https:/ en.wikipedia.org/wiki/Germain_Pilon\#/media/File:Pilon-risenchrist.jpg [dostęp: 17 sierpnia 2017]

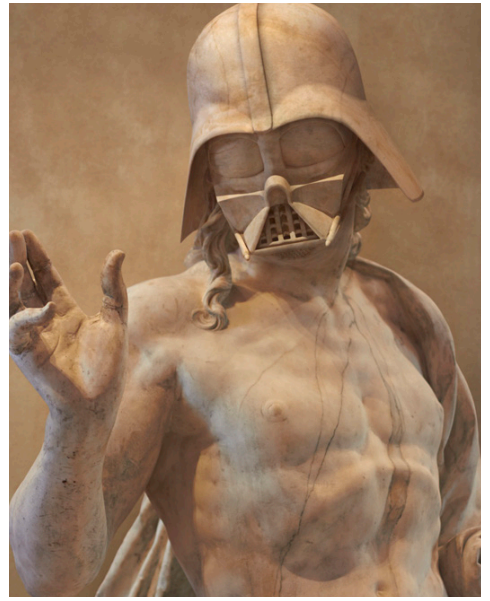

Ryc. 1b. Fotokolaz Travisa Durdena (1975-) Darth's Résurrection (2015). Fot. Travis Durden (c) http://travisdurden.com/index php/oeuvres [dostęp: 17 sierpnia 2017]

Przyjrzyjmy się wszystkim dziewięciu fotokolażom i rzeźbom z Luwru, które Durden wybrał do swojego projektu. Najbardziej szokujące zestawienie prezentuje fotokolaż pt. Darth's Résurrection. Wyobrażenie głowy Dartha Vadera zostało połączone $\mathrm{z}$ ciałem Jezusa z rzeźby francuskiego rzeźbiarza renesansowego Germaina Pilona, stanowiącej część grupy La Résurrection (ok. 1572). Artysta skomentował tę kompozycję w następujących słowach: 
I also imagined Darth Vader as a great sage, returning among the living. [... My favorite character is Darth Vader, a nice Jedi who became a villain to save his beloved wife Padmé Amidala ${ }^{14}$.

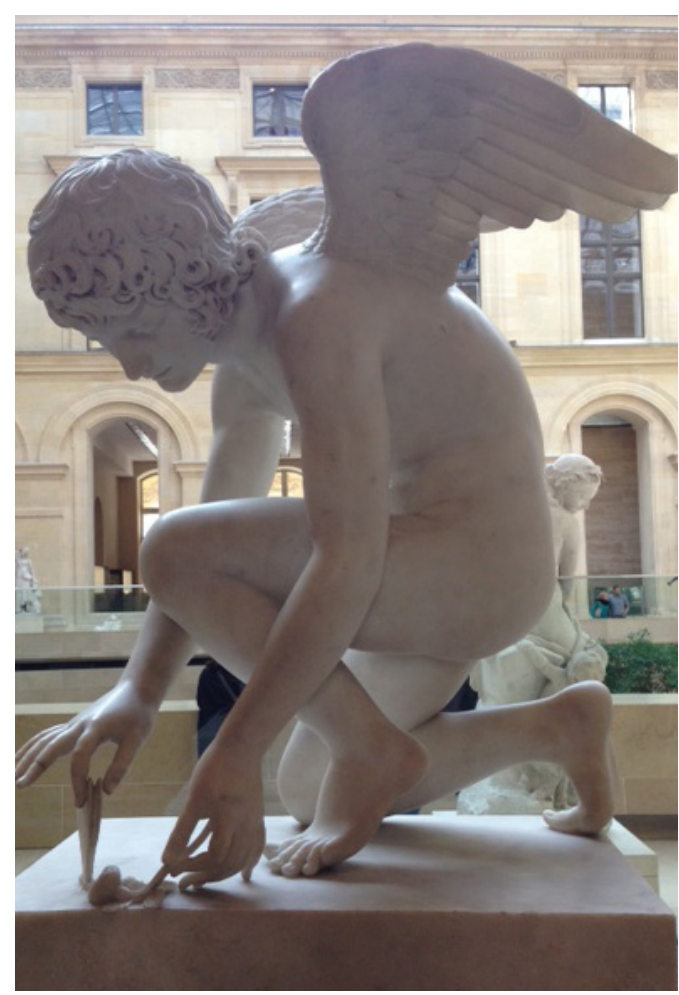

Ryc. 2a. Antoine-Denis Chaudet (1763-1810). L'Amour (1802).

Marmur. Musée du Louvre. Fot. Vladoubido0o

(C) Wikimedia Commons, https:/commons.wikimedia.org/ wiki/File:Chaudet_1\%27Amour.JPG?uselang=fr [dostęp: 17 sierpnia 2017]

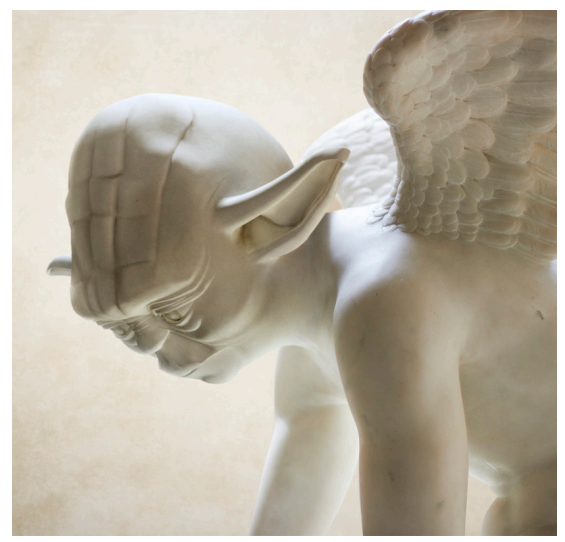

Ruc. 2b. Fotokolaz Travisa Durdena (1975-), Yodea Angel (2015). Fot. Travis Durden (C) http://ravisdurden.com/index.php/oeuvres [dostęp: 17 sierpnia 2017]

Drugą ze wspomnianych w zacytowanej przed chwilą wypowiedzi Durdena postaci, Mistrza Jedi, artysta utożsamił z cherubinem w wersji klasycystycznej autorstwa francuskiego rzeźbiarza Antoine’a-Denisa Chaudeta (L’Amour). Fotokolaż z cherubinem o głowie mistrza Jedi otrzymał nazwę Yodea Angel. 


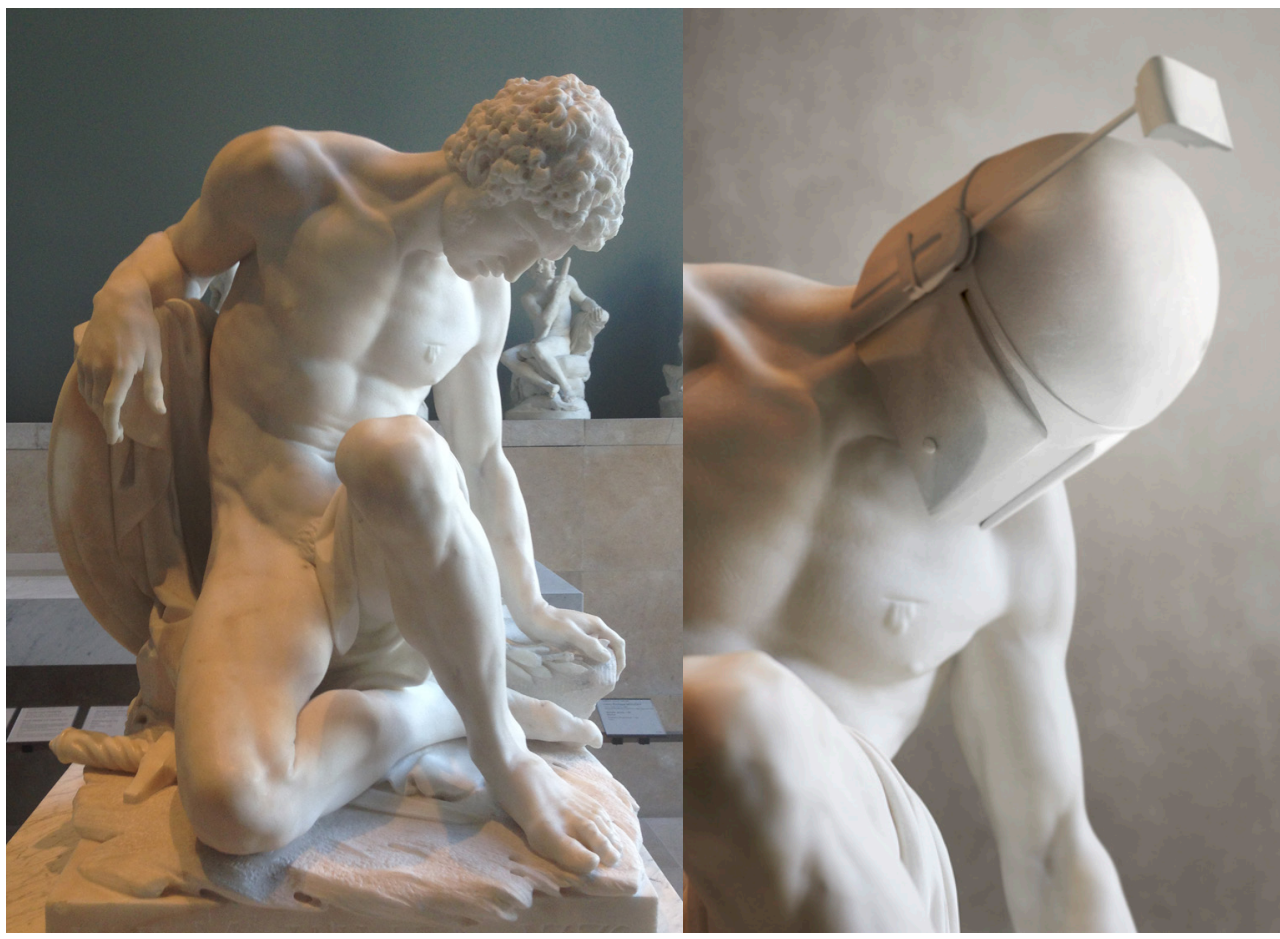

Ryc. 3a. Pierre Julien (1731-1804), Gladiateur mourant

(1779). Marmur. Musée du Louvre. Fot. Vladoubido0o

(c) Wikimedia Commons, https//upload wikimedia.

org/wikipedia/commons/f/f3/Pierre_Julien_Gladia-

teur_mourant.jpg [dostęp: 17 sierpnia 2017]
Ruc. 3b. Fotokolaz Travisa Durdena (1975-),

Gladiator Boba (2015). Fot. Travis Durden

(C) http//travisdurden.com/index.php/oeu-

vres [dostęp: 17 sierpnia 2017]

Słynny łowca nagród, niezmodyfikowany klon Jango Fetta - Boba Fett - to kolejny bohater Gwiezdnych wojen wyróżniony przez artystę. Jego głowa została złączona z ciałem rzeźby pt. Gladiateur mourant dłuta Pierre’a Juliena (1779), przedstawiającej umierającego gladiatora. Powstała w ten sposób kreacja otrzymała nazwę Gladiator Boba. 


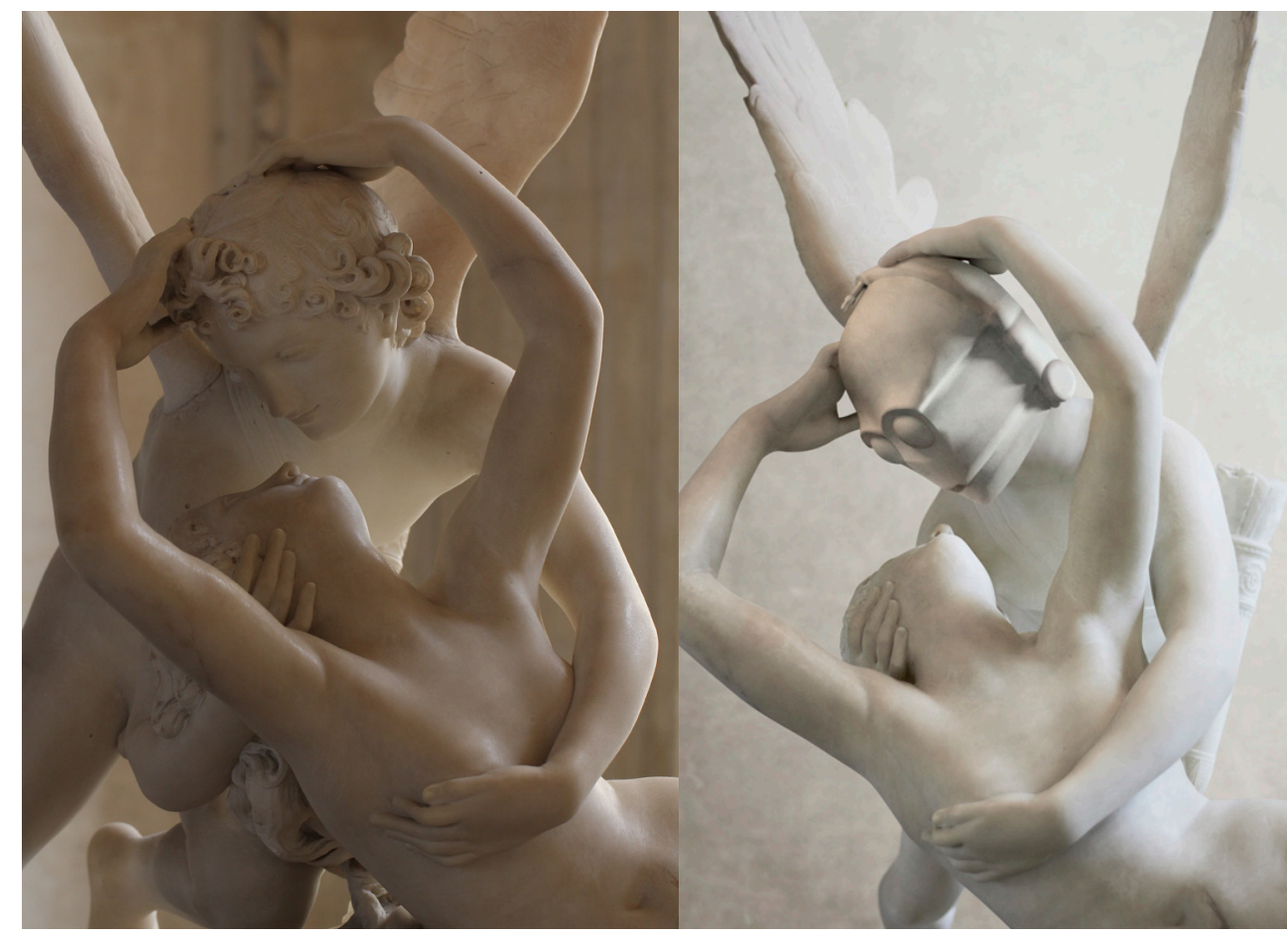

Ryc. 4a. Antonio Canova (1757-1822), Psyché ranimée par le baiser de l'Amour (1786-1793). Marmur. Musée du Louvre. Fot. J. Bittner Unna

(c) Wikimedia Commons, https://commons. wikimedia.org/wiki/File:Amor-Psyche-Canova-JBU04.JPG [dostęp: 17 sierpnia 2017]

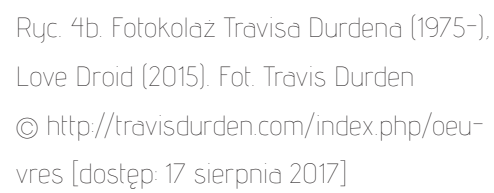

$\left(1975^{-}\right)$

(c) http://travisdurden.com/index.php/oeuvres [dostęp: 17 sierpnia 2017]

Jedna z najsłynniejszych rzeźb klasycystycznych, Psyché ranimée par le baiser de l'Amour (1786-1793) autorstwa Antonia Canovy, stała się natomiast bazą do przedstawienia nowej wersji jednej z najważniejszych postaci uniwersum Gwiezdnych wojen, robota protokolarnego z planety Tatooine - C3PO, skonstruowanego przez młodego Anakina Skywalkera. Nowe, zaskakujące wcielenie droida, który zyskał miano Love Droid, zostało zinterpretowane przez twórcę w następujących słowach:

A robot is incapable of human feelings but $\mathrm{C} 3 \mathrm{PO}$ is controlling more than 6 million forms of communication, $[\ldots]$ we can imagine that one of them is love ${ }^{15}$. 

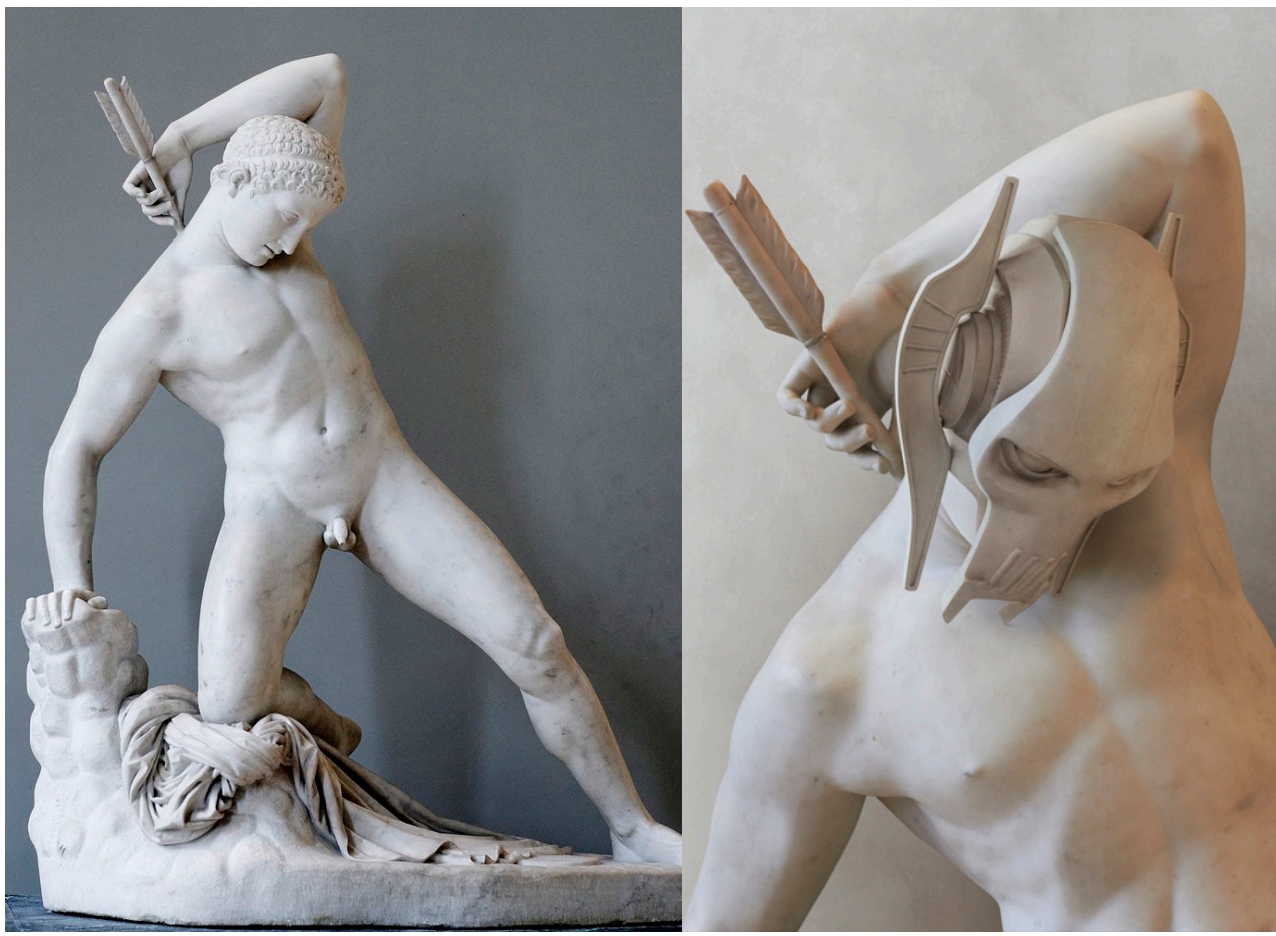

Ryc. 5a. James Pradier (1790-1852), Niobide blessé

Ruc. 5b. Fotokolaz Travisa Durdena (1975-),

(1822]. Marmur. Musée du Louvre. Fot. Jastrow

General Niobides (2015). Fot. Travis Durden

(C) Wikimedia Commons, https//commons.wikimedia

(C) http//travisdurden.com/index.php/oeu ${ }^{-}$

org/wiki/File:Niobid_Pradier_Louvre_LL312.jpg [do-

vres [dostęp: 17 sierpnia 2017]

stęp: 17 sierpnia 2017]

Powstała w Rzymie w początkach XIX stulecia rzeźba Jeana Jacques’a Pradiera pt. Niobide blessé (1822) po przemodelowaniu przez Durdena otrzymała nazwę General Niobides. Durden przekształcił Niobidkę w generała Grievousa (wcześniej znany jako Qymaen jai Sheelal) ${ }^{16}$, naczelnego dowódcę sił zbrojnych Separatystów. Artysta tak charakteryzuje tę postać:

Grievous is supposed to be indestructible, but I imagine he could die with a simple arrow in the back... ${ }^{17}$.

16 „Grievous” to pseudonim wyrażający stan, w jakim generał znalazł się po śmierci towarzyszki życia (z jęz. ang. grievous - 'zrozpaczony').

17 „Hartford Courant”, dz. cyt. 

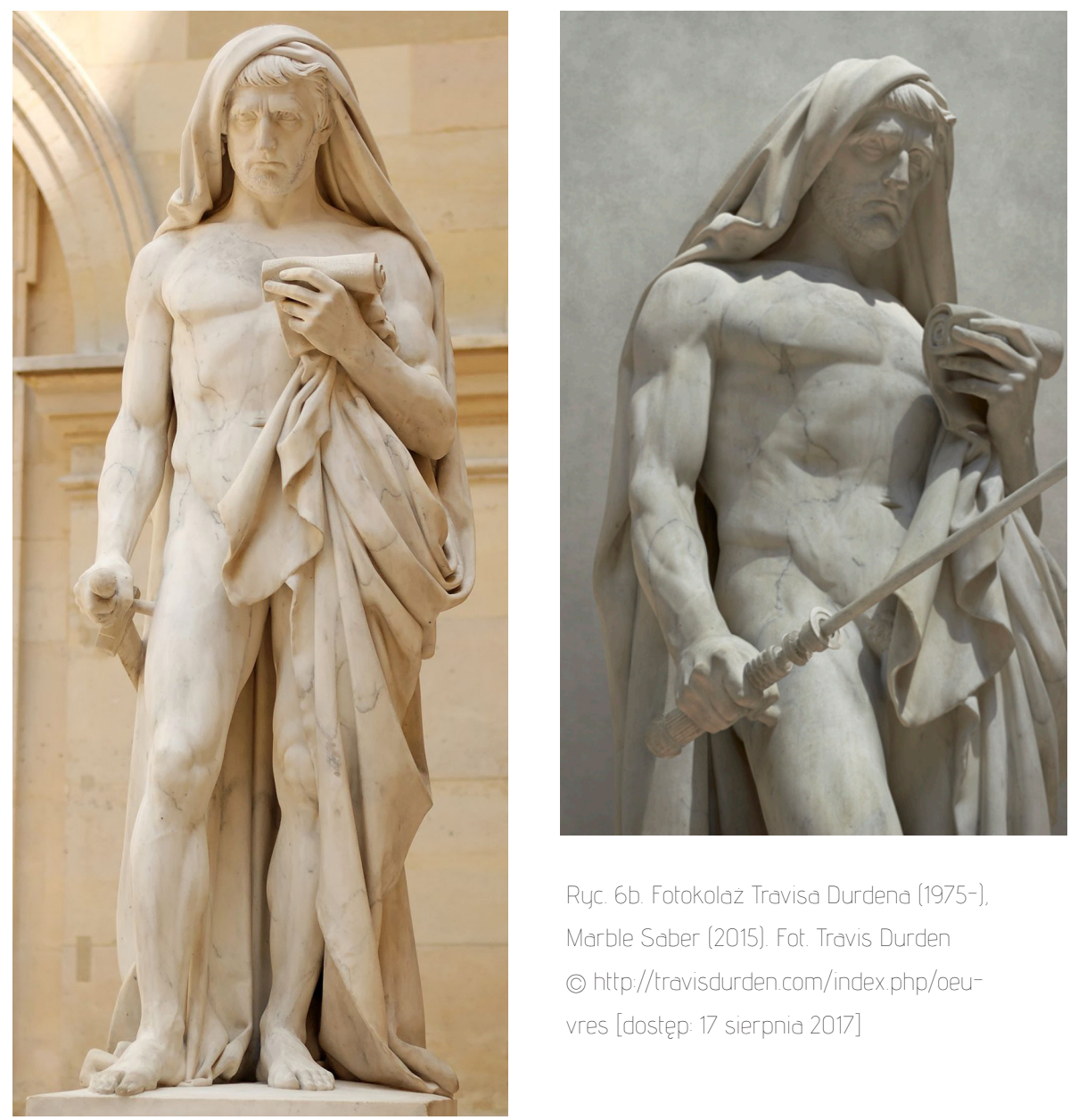

Ruc 6b. Fotokolaz Travisa Durdena (1975-), Marble Saber (2015). Fot. Travis Durden

(c) http://ravisdurden.com/index.php/oeuvres [dostęp: 17 sierpnia 2017]

Ryc. 6a. Jean-Baptiste Roman (1792-1835), François Rude (1784-1855). Caton d’Utique lisant le Phédon avant de se donner la mort (1840). Marmur. Musée du Louvre. Fot. Jastrow

(C) Wikimedia Commons,

Rzeźba Jeana-Baptiste’a Romana, ukończona przez François Rude’a, nosząca tytuł Caton d'Utique lisant le Phédon avant de se donner la mort (1832), po cyfrowym przemodelowaniu otrzymała nazwę Marble Saber. Mężczyzna trzyma „marmurową” kopię miecza świetlnego, tradycyjnej broni rycerzy Jedi. 


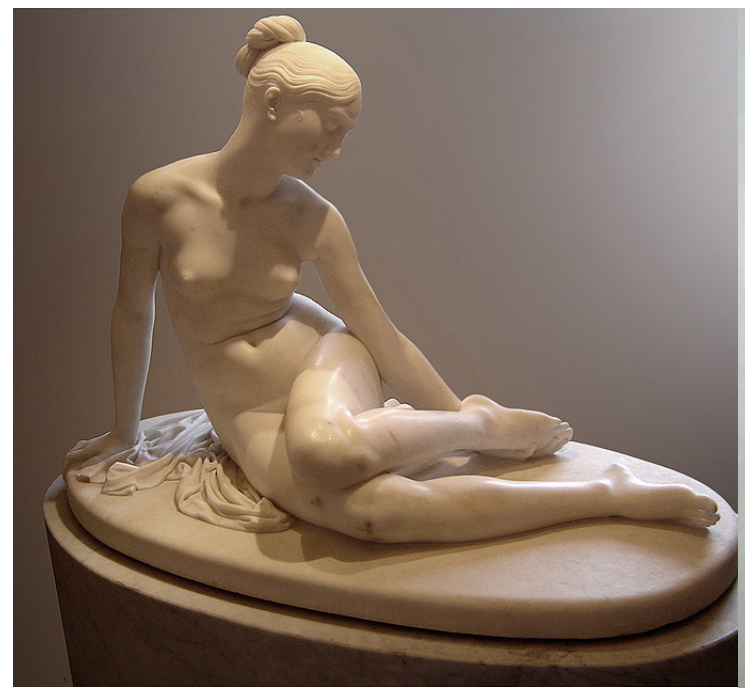

Ryc. 7a. Lorenzo Bartolini (1777-1850), Ninfa dello

Scorpione (1845). Marmur. Musée du Louvre

Fot. R.A. Frantz. () Wikimedia Commons.

https//dewikipedia.org/wiki/Lorenzo_Bartolini\#/media/File:Bartolini-ninfa2.jpg [dostęp: 17 sierpnia 2017]

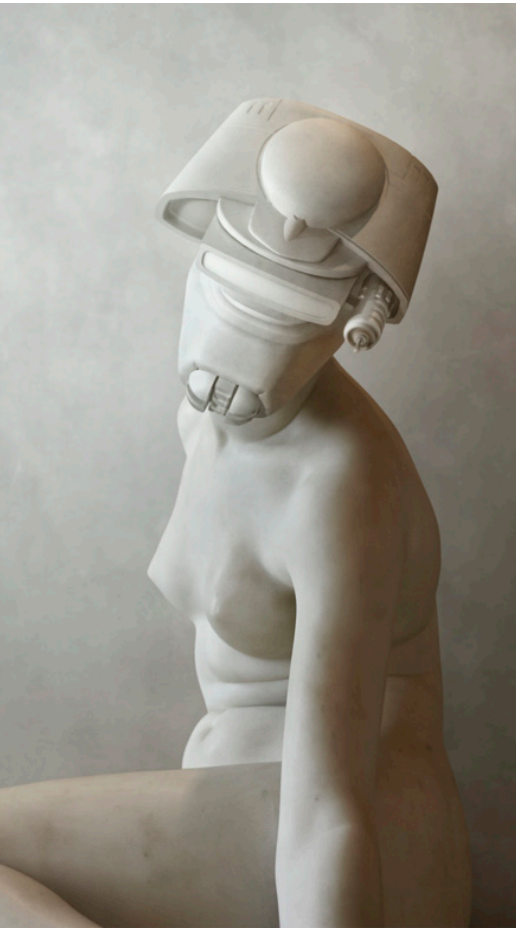

Ruc. 7b. Fotokolaz Travisa Durdena (1975-),

The Nymph, bounty hunter (2015)

Fot. Travis Durder

(c) http://travisdurden.com/index.php/oeuvres [dostęp: 17 sierpnia 2017]

The Nymph, bounty hunter to z kolei nazwa innej propozycji fotografa francuskiego, powstałej z inspiracji rzeźbą neoklasycystyczną autorstwa Lorenza Bartoliniego pt. Ninfa dello Scorpione (1845). Bounty Hunter to bohater gry wideo (Star Wars: Bounty Hunter) wyprodukowanej w 2002 roku w amerykańskiej LucasArts Entertainment Company (LLC) ${ }^{18}$ dla GameCube i PlayStation 2.

18 Firma została założona przez George’a Lucasa w 1982 r. jako Lucasfilm Games. W 1990 r. została przemianowana na LucasArts. 


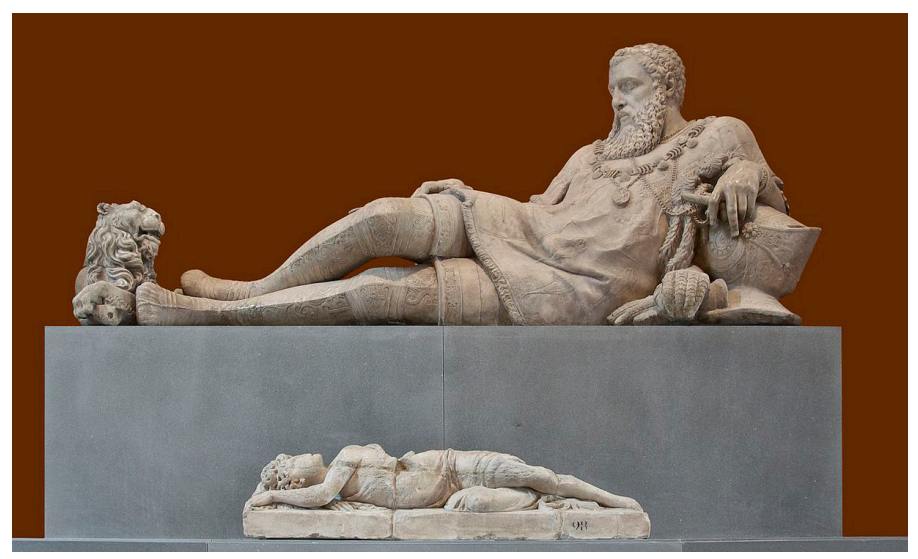

Ruc. 8a. Autor nieznany.

Tombeau de Philippe Chabot

(XV1 w.): Alabaster. Musée du

Louvre. Fot. Jebulon

(C) Wikimedia Commons,

https:/commonswikimedia.

org/wiki/File:Tombeau_Philip-

pe_Chabot_Louvre_MR1779_

orange.jpg

[dostęp: 17 sierpnia 2017]

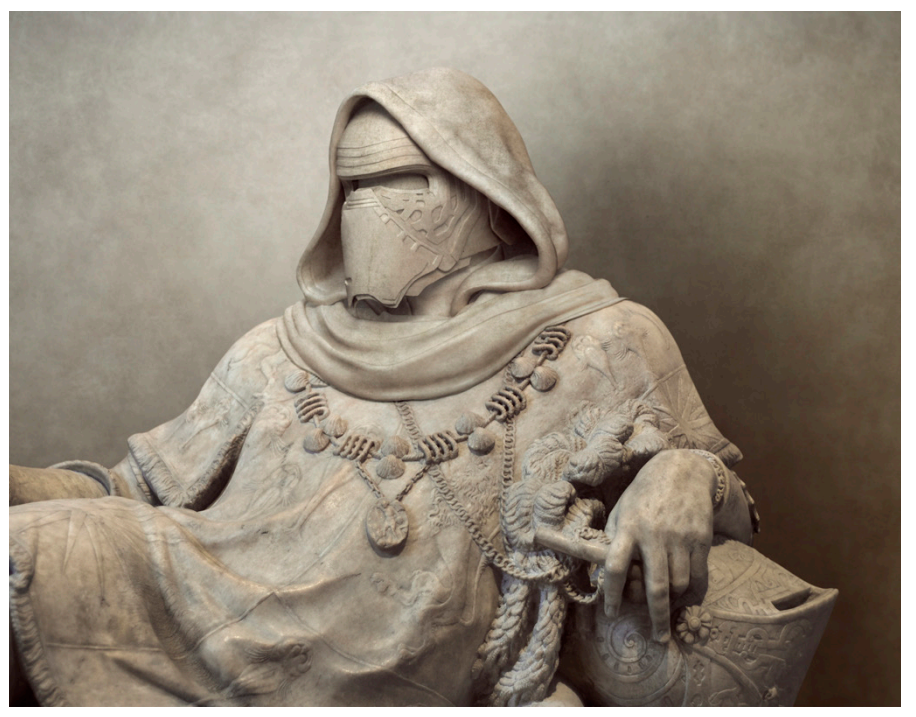

Ruc 8b. Fotokolaz Travisa

Durdena (1975-), Amiral de

Ren (2015). Fot. Travis Durden

(c) http//travisdurden.com/

index.php/oeuvres

[dostęp: 17 sierpnia 2017]

Fotokolaż zatytułowany Amiral de Ren powstał z cyfrowego przekształcenia fragmentu rzeźby z grobu Philippe’a Chabota (1480-1543), znanego jako Admirał De Brion, admirała Francji z XVI wieku. 


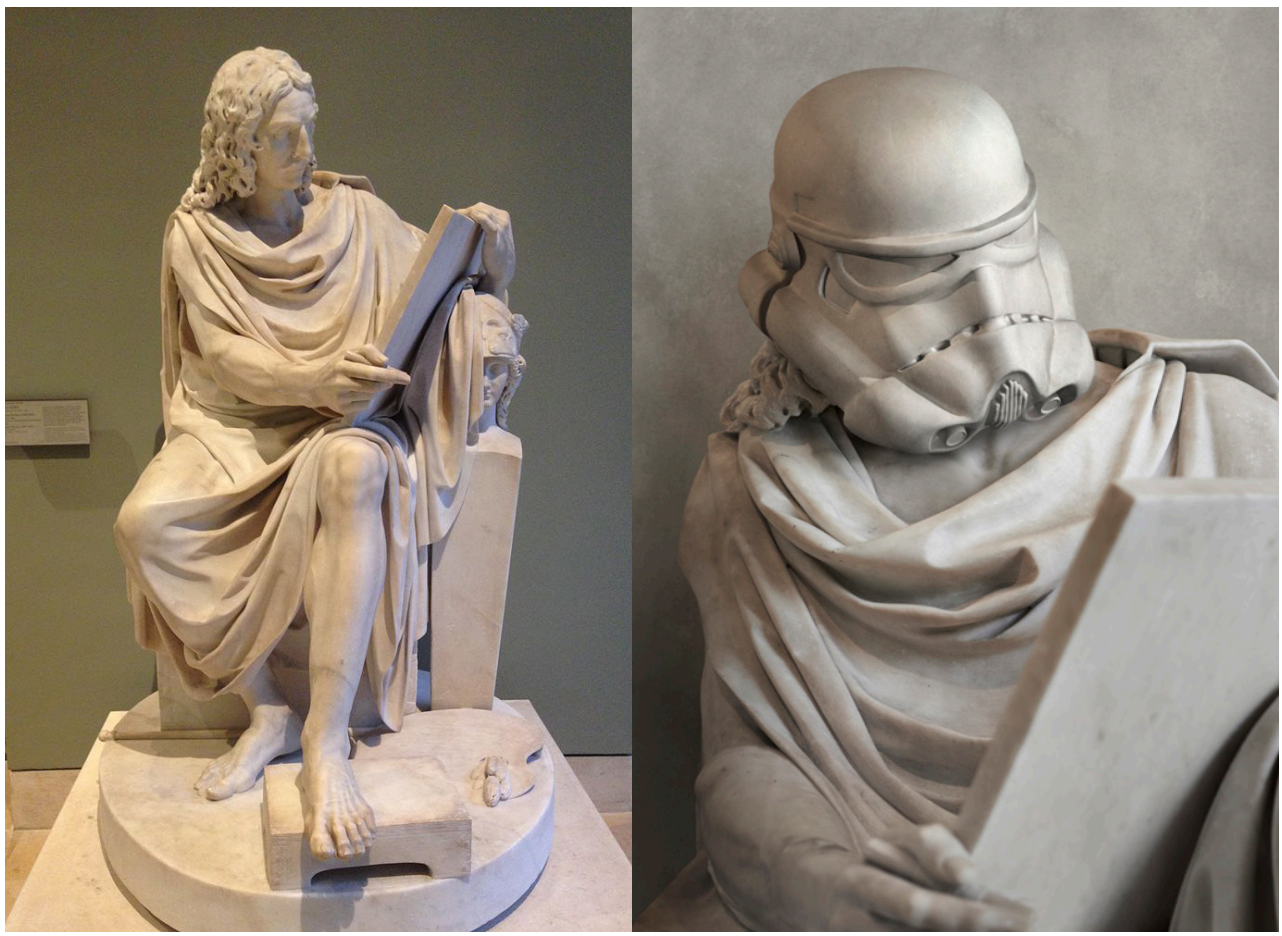

Ryc. 9a. Pierre Julien (1731-1804), Nicolas Poussin

(1822). Marmur. Musée du Louvre. Fot. VladoubidoOo

(c) Wikimedia Commons, https//commons.wikimedia org/wiki/Category:Pierre_Julien?uselang=fr\#/media/ File:Pierre_Julien_Poussin.jpg [dostęp: 17 sierp-
Ruc. 9b. Fotokolaz Travisa Durdena (1975-), Storm Reader (2015). Fot. Travis Durden (c) http://travisdurden.com/index.php/oeuvres [dostęp: 17 sierpnia 2017] nia 2017]

Ostatnia kreacja Durdena, zatytułowana Storm Reader, powstała z komputerowego przemodelowania rzeźby Pierre’a Juliena pt. Nicolas Poussin, przedstawiającej słynnego malarza klasycyzmu francuskiego (1594-1665) czytającego książkę (1804). W kreacji Durdena czytającym jest fikcyjna postać z Gwiezdnych wojen, jeden ze szturmowców Imperium ubrany w tradycyjny biały pancerz. Durden wyjaśnia, co widział w tej postaci:

I imagine $[\ldots]$ a Storm Trooper, who opposes his clone condition by reading a book ${ }^{19}$. 
Podczas interpretacji projektu Durdena najgorsze, co można zrobić, to sprowadzić go do poziomu produktu współczesnej komputerowej techniki cyfrowej i reklamy uniwersum Gwiezdnych wojen. To zdecydowanie coś więcej. Tworząc amalgamat produktu współczesnej kultury masowej, jakim są Gwiezdne wojny, z rzeźbiarskimi arcydziełami nowożytnej (renesansowej, klasycystycznej i neoklasycystycznej) sztuki rzeźbiarskiej, przywołującymi nierzadko tematykę antyczną, artysta wiele osiągnął. Zgodnie z założeniem wywołał w odbiorcy swojej sztuki refleksję na temat konsumowania kultury dziś i w przeszłości - przeszłości, która tak bardzo zaważyła na scenariuszu filmu ${ }^{20}$. Zobrazował podobieństwa pomiędzy obiektami kultu o różnorodnej proweniencji chronologicznej, pokazując w ten sposób, że proces konstrukcji mitów przez ludzi jest analogiczny niezależnie od czasu i miejsca. Ponadto ten być może w niektórych przypadkach kontrowersyjny mish-up - przetworzone cyfrowo w komputerze fotografie nowożytnych dzieł rzeźbiarskich, „pożenione” z atrybutami bohaterów Gwiezdnych wojen - niesie gębokie i mądre przesłanie. Ma uzmysłowić nie tylko współczesnym, lecz także przyszłym pokoleniom ogromną wartość dziedziczonego przez nas dorobku kulturowego - przede wszystkim antycznego, ale również późniejszego, nowożytnego ${ }^{21}$, co w dobie umasowienia kultury ma szczególnie istotne znaczenie. Idea zachowania dla potomności kulturowego dorobku minionych pokoleń wyziera z każdej z dziewięciu kreacji Durdena. On sam mówi o tym na swojej stronie internetowej

Bringing together ancient classical art and modern culture is a way for the latter to contribute to the preservation of the former, it is an invitation to go back and rediscover our ancestors' work before we, the general public, forget about them ${ }^{22}$.

Travis Durden zrealizował w pełni swoje założenia. Osiągnął nawet więcej. Myths and Idols to przykład podwójnej recepcji kultury antycznej - nowożytnej i tej współczesnej, nie tylko europejskiej. Dzieła rzeźbiarskie, które Durden wybrał do swojego projektu, są autorstwa artystów europejskich (rzeźbiarze francuscy i jeden włoski) i mają wyłącznie proweniencję nowożytną (renesans, klasycyzm, neoklasycyzm). Nie ma wśród nich żadnego dzieła sztuki antycznej, a więc sama sztuka klasyczna

20 Tamże: „By mixing the two periods, I hope to bring people to think back on how we consume culture”; „to realize that nothing in 'Star Wars' would have been imagined if it hadn't been for past heroes written a long time ago, in lands far far away".

21 Autora zainteresowały nowożytne interpretacje sztuki klasycznej. Niektórzy dziennikarze omyłkowo, jak można przypuszczać, skoncentrowali swoją uwagę na epoce wcześniejszej (klasycznej), co spowodowało, że zarówno w nagłówkach artykułów i notatek prasowych, jak i w samych artykułach jest mowa wprost o zestawianiu ze sobą dzieł sztuki antycznej (greckiej) z bohaterami Gwiezdnych wojen.

22 https://www.facebook.com/pg/travisdurden/about/?ref=page_internal. 
(starożytna) zainteresowała artystę przez pryzmat sztuki nowożytnej, której twórcy chętnie przecież naśladowali wzorce antyczne i podejmowali tematykę starożytną. Z kolei Gwiezdne wojny to produkt współczesnej amerykańskiej kultury popularnej. Myths and Idols to pierwszy projekt artystyczny Travisa Durdena i, co trzeba podkreślić, niezwykle udany. Dzięki oryginalności, szokującej konfrontacji tak zwanej sztuki wysokiej z kulturą masową artysta błyskawicznie zyskał międzynarodową popularność. Jego fotokolaże prezentowane były i są na wystawach w rodzimej Francji ${ }^{23}$ i w Stanach Zjednoczonych ${ }^{24}$, a także między innymi w Niemczech ${ }^{25}$ i w Szwajcarii ${ }^{26}$. Obok fotografii o tematyce gwiezdnowojennej autorstwa innych artystów prace wystawiono również w Callais (wzdłuż ulicy Digue Gaston Berthe, tuż przy plaży). Organizatorem tego przedsięwzięcia była paryska Galerie Sakura ${ }^{27}$. Na temat projektu fotograficznego Myths and Idols prasa międzynarodowa rozpisywała się chętnie i dużo. Co interesujące, a zarazem obiecujące i optymistyczne, jeśli chodzi o naszą i potomnych pamięć o kulturze antycznej - wielu autorów artykułów i notatek prasowych komentujących projekt Myths and Idols dostrzegło w fotokolażach Durdena głównie ów antyczny wymiar, pomijając niekiedy fakt, że Durden wykorzystał do swojego projektu wyłącznie rzeźby nowożytne ${ }^{28}$.

23 Galerie Sakura w Paryżu od 10 października 2015 do 29 lutego 2016 r.

24 W USA odbyły się dwie wystawy: w Hartford w stanie Connecticut (EBK Gallery, 218 Pearl St.; strona internetowa wystawy: http://ebkgallery.com/gallery/travis-durden/) od 22 grudnia 2014 do 21 lutego 2015 r. i w Nowym Jorku (Caelum Gallery, 508/526 West 26th Street / Suite 315, New York, NY 10001), gdzie fotokolaże były wystawiane w styczniu 2016 r. i od 22 marca 2016 do 8 kwietnia 2016 r.; strona internetowa galerii: http://www.caelumgallery.com/\#!travis-durden/c161b.

25 Fotokolaże prezentowano podczas Artfair Berliner Liste od 15 do 17 września $2017 \mathrm{r}$.

26 WYverdon les Bains w Ailleurs Museum, od 10 grudnia 2017 do 14 października 2018 r. Wystawa nosiła nazwę Je suis ton père.

27 Od 18 czerwca do 18 września 2016 r. Obok prac Travisa Durdena zaprezentowano dzieła następujących artystów: David Eger, Hyperactive Studio, Marc Ninghetto, Steven Hollingsworth, Agan Harahap, Cihan Ünalan, Dan Picard, Guilhem Lascaux, Ian Basen, Lewis Forde, Marc Trautmann, Pete Ware, Grégoire Guillemin.

28 Por. np. artykuły w magazynach - „Designboom”: Travis Durden Solidifies Star Wars Characters as Ancient Greek Statues. Autorka artykułu pisze o „synthesis of contemporary culture and classical sculpture” [online], 6 listopada 2015 [dostęp: 29 czerwca 2017]. Dostępny w World Wide Web: http://www.designboom.com/art/travis-durden-star-wars-greek-statues-11-06-2015/; magazyn „Boulevard”: 'Star Wars' Characters as Ancient Greek Statues. Czytamy tam: „French artist Travis Durden digitally sculpted your favorite Star Wars characters and transformed them into great ancient Greek statues” [online], 12 grudnia 2015 [dostęp: 16 sierpnia 2017]. Dostępny w World Wide Web: http://magzblvd.com/star-wars-characters-as-ancient-greek-statues/; strona internetowa „Pics in Pics”: tytul posta - Star Wars Characters Reimagined as Ancient Greek Statues by French Artist Travis Durden i początek tekstu: „I've never specifically asked myself what Yoda and Darth Vader might look like if reimagined as classical Greek nudes, but I can't say I'm disappointed that somebody made this non-dream a reality" [online], [dostęp: 16 sierpnia 2017]. Dostępny w World Wide Web: http://picsinpics.com/art/star-wars-characters-reimagined-as-ancient-greek-statues-by-french-artist-travis-durden.html; blog „Área Visual” i artykuł: Travis Durden. Esculturas clásicas de Star Wars [online], 13 stycznia 2016 [dostęp: 16 sierpnia 2017]. Dostępny w World Wide Web: http://www.area-visual.com/2016/01/travis-durden-esculturas-clasicas-de.html; kanadyjski portal promujący sztukę nowoczesną „Booooooom”: Star Wars Characters Reimagined as Greek Sculptures [online], 15 grudnia 2017 [dostęp: 28 czerwca 2017]. Dostępny w World Wide Web: http://www.booooooom.com/2015/12/15/ 


\section{BIBLIOGRAFIA}

Brode D., Deyneka L. (eds.), Myth, Media, and Culture in Star Wars: An Anthology, Lanham-Toronto-Plymouth 2012.

McDowell J.C., „Unlearn what you have learned” (yoda): The Critical Study of the Myth of Star Wars [w:] Understanding Religion and Popular Culture. Theories, Themes, Products and Practices, ed. by T.R. Clark, D.W. Clanton, Jr., New York 2012, s. 104-117.

Gordon A., Star Wars: A Myth for Our Time, Literature, „Film Quarterly” 1978, 6.4, s. 314-326.

Henderson M., Star Wars: The Magic Myth, New York 1997.

Kapell M.W., Lawrence J.S. (eds.), Finding the Force of the Star Wars Franchise. Fans, Merchandise, \& Critics, New York 2006.

Kinnucan M.J., Pedagogy of (the) Force: The Myth of Redemptive Violence [w:] Finding the Force of the Star Wars Franchise. Fans, Merchandise, \& Critics, ed. by M.W. Kapell, J.S. Lawrence, New York 2006, s. 59-74.

Lawrence J.S., Joseph Campbell, George Lucas and the Monomyth [w:] Finding the Force of the Star Wars Franchise. Fans, Merchandise, \& Critics, ed. by M.W. Kapell, J.S. Lawrence, New York 2006, s. 21-34.

McVeight S.P., The Galactic Way of Warfare [w: ] Finding the Force of the Star Wars Franchise. Fans, Merchandise, \& Critics, ed. by M.W. Kapell, J.S. Lawrence, New York 2006, s. 35-58.

Silvio C., Vinci T.M. (eds.), Culture, Identities and Technology in the Star Wars Films: Essays on the Two Trilogies, Jefferson 2007.

Star Wars Art: Visions, New York 2010.

Star Wars Art: Comics, New York 2011.

Star Wars Art: Illustration, New York 2012.

Star Wars Art: Concept, New York 2013.

star-wars-characters-reimagined-as-greek-sculptures/; dziennik „Haaretz” [online], 16 grudnia 2015 [dostęp: 27 czerwca 2017]. Dostępny w World Wide Web: http://www.haaretz.co.il/gallery/art/1.2784955; strona www.littlethings.com: „By combining Star Wars characters with classic Greek statues, he's created a combination of past and present, ancient and modern, and high and low culture" [online], [dostęp: 2 lipca 2017]. Dostępne w World Wide Web: https://www.littlethings.com/travis-durden-star-wars-sculptures/. Zob. też „Metro Nicaragua": Mitología griega a lo Star Wars [online], 3 grudnia 2015 [dostęp: 1 lipca 2017]. Dostępny w World Wide Web: http://diariometro.com.ni/espectaculos/55933-fotos-mitologia-griega-a-lo-star-wars/; S. Meineck, Darth Vader saugt, „Der Spiegel” [online], 7 grudnia 2015 [dostęp: 2 lipca 2017]. Dostępny w World Wide Web: http://www.spiegel.de/netzwelt/web/star-wars-alltag-von-darth-vader-a-1066458.html. Ciekawy i ważny artykuł wraz z wywiadem ukazał się w największej w stanie Connecticut gazecie codziennej - „Hartford Courant”. W artykule zatytułowanym French Artist Manipulates Statues to Create 'Star Wars' Photos reporterka Susan Dunne przedstawia nie tylko wizję artysty, lecz również identyfikuje każde z pierwowzorów dzieł, które Durdenowi posłużyły jako baza do dalszej pracy twórczej; S. Dunne, dz. cyt. 
Star Wars Art: Posters, New York 2014.

The Art of Star Wars: The Force Awakens, New York 2015.

\section{PUBLIKACJE DOSTĘPNE W INTERNECIE}

http://www.travisdurden.com

https://www.galerie-sakura.com

https://www.facebook.com/travisdurden

https://www.instagram.com/travis_durden_art

http://ebkgallery.com/gallery/travis-durden/

http://www.caelumgallery.com/\#!travis-durden/c161b

Caseley L., Past and Present Collide with these Reimagined 'Star Wars' [online], [dostęp: 2 lipca 2017]. Dostępny w World Wide Web: https://www. littlethings.com/travis-durden-star-wars-sculptures/.Dunne S., French Artist Manipulates Statues to Create Star Wars Photos, „Hartford Courant” [online], 30 grudnia 2015 [dostęp: 18 marca 2017]. Dostępny w World Wide Web: http://www.courant.com/entertainment/museums-galleries/hc-ebk-gallery-star-wars0103-20151230-story.html

„Hartford Courant” [online], 30 grudnia 2015 [dostęp: 18 marca 2017]. Dostępny w World Wide Web: http://www.courant.com/entertainment/ museums-galleries/hc-ebk-gallery-star-wars-0103-20151230-story.html

Lucas G., Of Myth and Men: A Conversation between Bill Moyers and George Lucas on the Meaning of the Force and the True Theology of Star Wars, „Time” 153.16 [online], 18 kwietnia 1999, s. 91-94 [dostęp: 11sierpnia 2017]. Dostępny w World Wide Web: http://content.time.com/time/magazine/article/ 0,9171,23298,00.html.

Meineck S., Darth Vader saugt, „Der Spiegel” [online], 7 grudnia 2015 [dostęp: 2 lipca 2017]. Dostępny w World Wide Web: http://www.spiegel.de/ netzwelt/web/star-wars-alltag-von-darth-vader-a-1066458.html.

Mitología griega a lo Star Wars, „Metro Nicaragua” [online], 3 grudnia 2015 [dostęp: 1 lipca 2017]. Dostępny w World Wide Web: http://diariometro.com.ni/ espectaculos/55933-fotos-mitologia-griega-a-lo-star-wars/.

Star Wars' Characters as Ancient Greek Statues, „Magazyn Boulevard” [online], 12 grudnia 2015 [dostęp: 16 sierpnia 2017]. Dostępny w World Wide Web: http://magzblvd.com/star-wars-characters-as-ancient-greek-statues/. 
Star Wars Characters Reimagined as Ancient Greek Statues by French Artist Travis Durden [online], [dostęp: 16 sierpnia 2017]. Dostępny w World Wide Web: http://picsinpics.com/art/star-wars-characters-reimagined-as-ancient-greek-statuesby-french-artist-travis-durden.html.

Star Wars Characters Reimagined as Greek Sculptures, „Booooooom” [online], 15 grudnia 2017 [dostęp: 28 grudnia 2017]. Dostępny w World Wide Web: http:// www.booooooom.com/2015/12/15/star-wars-characters-reimagined-as-greeksculptures/.

Travis Durden. Esculturas clásicas de Star Wars [online], 13 stycznia 2017 [dostęp: 16 sierpnia 2017]. Dostępny w World Wide Web:

http://www.area-visual.com/

2016/01/travis-durden-esculturas-clasicas-de.html.

Travis Durden solidifies Star Wars characters as ancient Greek statues, „Designboom” [online], 6 listopada 2015 [dostęp: 29 czerwca 2017]. Dostępny w World Wide Web: http://www.designboom.com/art/travis-durden-star-warsgreek-statues-11-06-2015/.

הנותאב רדייו 'תראד :םיבכוכה תמחלמ, ,Haaretz” [online], 16 grudnia 2015 [dostęp: 27 czerwca 2017]. Dostępny w World Wide Web: http://www.haaretz.co.il/gallery/art/1.2784955. 